\title{
Os guarani no oeste paranaense e a (re)constituição de territórios originários
}

\author{
The guarani in the west of paraná and the (re) constitution of territories of origin
}

\author{
Rubia Carla Formighieri Giordani ${ }^{1}$
}

\begin{abstract}
Resumo
Se o problema do território é uma constante entre os guarani dos estados das regiões Sul e Sudeste, uma das particularidades vivenciadas pela etnia no Paraná foi a devastação rápida da porção do bioma da Mata Atlântica no segundo e terceiro planalto e as intensas transformações geopolíticas associadas ocorridas nos últimos 60 anos. Vivendo em área diminuta e cercados pelas fazendas de monocultura da região, as interferências acentuadas das perturbações de ordem ecológica e sociológica na vivência daquilo que denominam seu "modo de vida autêntico" é um desafio cotidiano para esses grupamentos. Trouxe neste artigo algumas referências históricas e etnográficas para problematizar a constituição do território originário e legítimo guarani, com interesse voltado às transformações no seu espaço social atual. À produção de uma etnografia, metodologicamente aliou-se pesquisa de informações históricas complementada pela história oral de velhas lideranças dos grupos atuais que vivem e circulam na região oeste do estado do Paraná, Brasil.
\end{abstract}

Palavras-chave: Território guarani; Espaço social; Cultura guarani.

\begin{abstract}
If the territory issue is a constant among the guarani of the states of the South and Southeast region of Brazil, one of the peculiarities experienced by the ethnicity in Paraná was the fast devastation of the portion of the Atlantic Forest biome in the second and third plateaus and the intense associated geopolitical changes that have occurred in the last sixty years. Living in a small area and surrounded by monoculture farms, the strong interference of ecological and sociological disruptions in living what they call their "authentic way of life" is a daily challenge for these groups. In this article we bring some historical and ethnographic references to discuss the establishment of the legitimate territory of origin of the guarani, with special interest in the transformations in their current social space. The production of ethnography was methodologically associated with historical information research complemented by the oral history of old leaders of the current groups who live and circulate in the western region of the state of Paraná, Brazil.
\end{abstract}

Keywords: Guarani territory; Social space; Guarani culture.

\section{Introdução}

Para Bartolomeu Meliá (1989, p. 249), o “Tupi-Guarani como língua e como cultura é o ramo do tronco Tupi mais antigo, a partir do qual toma características próprias e diferenciadoras, provavelmente a partir do primeiro milênio antes de Cristo, uns 3000 a 2500 anos atrás". Vestígios

\footnotetext{
${ }^{1}$ Doutora em Sociologia (UFPR) e em Etnologia (Paris X). Professora do Departamento de Nutrição da Universidade Federal do Paraná. E-mail: rubiagiordani@gmail.com.
} 
de uma existência poderosa da sociedade guarani em faixas de terras que ultrapassam as fronteiras do Brasil, Paraguai, Argentina e Uruguai têm sido registrados pela arqueologia (NOELLI, 2004).

Os guarani contemporâneos que vivem no Brasil dividem-se entre os mbya, ñandeva e kaiowá, possuindo particularidades tanto no dialeto quanto na cultura material e práticas rituais. Essas diferenças linguísticas e culturais foram usadas por Egon Schaden nos anos 1950 (1974) para estabelecer uma classificação que tem sido adotada desde então na literatura etnológica guarani.

Os guarani mbya contemporâneos vivem em aldeias do norte do Uruguai e da Argentina, na porção oriental do Paraguai, e nos estados do Sul do Brasil, além da área da Mata Atlântica de São Paulo, Rio de Janeiro e Espírito Santo (ASSIS e GARLET, 2004). Se há numerosas etnografias dos grupos mbya nos estados da região Sul, além da extensa faixa litorânea que se estende até o Espírito Santo (CICCARONE, 2001; LADEIRA, 2007, 2008; LITAIFF, 1996, 1999; MACEDO, 2009; MELLO, 2006; TEMPASS, 2010), pouco se sabe sobre aqueles que atualmente vivem no interior do estado do Paraná, especialmente grupos que circulam entre áreas na região do extremo oeste paranaense.

Se o problema do território é uma constante entre os guarani dos estados das regiões Sul e Sudeste (DARELLA, 2004; GARLET, 1997; LADEIRA, 2007, 2008; QUEZADA, 2007), uma das particularidades vivenciadas pela etnia no Paraná foi a devastação rápida da porção do bioma da Mata Atlântica nos segundo e terceiro planaltos e as intensas transformações geopolíticas associadas ocorridas nos últimos 60 anos. Vivendo em área diminuta e cercados pelas fazendas de monocultura da região, as interferências acentuadas das perturbações de ordem ecológica e sociológica na vivência daquilo que denominam seu "modo de vida autêntico" é um desafio cotidiano para esses grupamentos. Descritos como fundamentalmente religiosos (MELIÁ, 1989), donos de uma filosofia encorpada e sofisticada que os fizeram conhecidos na literatura antropológica e historiográfica pelo mito da Terra Sem Mal (CLASTRES, 1978), em tempos de escassez de matas esforçam-se para conciliar na prática um distinto discurso asceta (CADOGAN, 1997), agricultura e caça (SCHADEN, 1974), e o relativo isolamento do mundo dos brancos.

Este artigo traz algumas referências históricas e etnográficas para pensar a constituição do território originário e legítimo guarani, com interesse voltado às transformações no seu espaço social atual. Buscou-se articular esse contexto maior e genérico acerca da territorialização indígena às questões espaciais dos grupos contemporâneos que habitam no oeste do estado do Paraná. À produção de uma etnografia, metodologicamente aliou-se pesquisa de informações históricas complementada pela história oral de velhas lideranças dos grupos atuais. Inicialmente o texto traz considerações sobre os guarani históricos para em seguida problematizar a (re) ocupação e apropriação recente de espaços físicos regionais. Para tanto, toma como exemplo etnográfico a 
constituição de áreas no extremo oeste do estado do Paraná e sua constituição em espaços sociais nos termos de uso e produção nativos. Por fim, aventam-se alguns nexos entre o tema da Terra sem Mal, os deslocamentos e a mobilidade, questões essas fundamentais para a compreensão da noção de território entre os guarani.

\section{Os guarani históricos e os grupos atuais na região}

Irredutíveis ao tempo, constantes em sua permanência nesta terra agora transformada pela presença de Outros que foram trazidos por novos tempos, estes homens, ainda nossos contemporâneos, são os indígenas das terras baixas da América do Sul "que têm a mais continuada - e a mais intrigante - presença até os dias de hoje”, diz Bartolomeu Meliá nos inspirando sobre as permanências de uma cultura quando prefaciou "Ladeira" (2007).

A presença dos grupos associados ao antropológico, linguístico ou arqueológico denominador comum chamado guarani alude a um amplo conjunto de grupamentos humanos que viveram em um mundo outro. Estima-se que há 2000 anos chegaram ao território que atualmente chamamos de terras paraguaias, uruguaias, argentinas e brasileiras populações pertencentes à família linguística Tupi-guarani (MELIÁ, 1989, p. 249). Nesse vasto território que se delimita entre as bacias dos rios Uruguai, Paraná e Paraguai até a costa atlântica e se estende do Trópico de Capricórnio ao rio da Prata foi identificado um conjunto de material cerâmico apresentando baixa variação cultural que sugere a reprodução de um estilo tecnológico superior a 1500 anos (LA SALVIA e BROCHADO, 1989; NOELLI, 2004).

Estudos arqueológicos, etnológicos e em linguística histórica comparada comportam dados e análises que indicam referenciais essencialmente amazônicos à cultura guarani (NOELLI, 2004). Rotas migratórias que partiram possivelmente do sudeste da Amazônia, nas bacias dos rios Madeira e Guaporé, atualmente estado de Rondônia, desceram ao centro-oeste (com evidências arqueológicas no Mato Grosso do Sul), estendendo-se pelos rios Paraná e Paraguai, ocuparam partes do Brasil meridional, alcançando toda a bacia continental da Prata (MOTA e NOVAK, 2008; NOELLI, 2004). Seguiram percorrendo "sus afluyentes hasta los interfluvios siempre em el interior de las selvas donde abrían claros para instalar sus aldeas, rozas, senderos y otras actividades ecológicas y sociales” (NOELLI, 2004, p. 18). Alcançaram as florestas subtropicais do Alto Paraná, bosques do Uruguai médio, Paraguai oriental e noroeste da Argentina, onde mantinham vasto domínio sobre esses territórios até os primeiros contatos com os europeus que chegaram no início do século XV. 
Essa população ceramista e agricultora mantinha, conforme demonstram os dados de escavações arqueológicas, um padrão de expansão e ocupação de novos espaços sem o abandono de áreas antigas (BROCHADO, 1977; MOTA e NOVAK, 2008). Mota e Novak (2008, p. 27) aventam como causa da divisão de um grupo local o incremento populacional ou problemas políticos quando os novos bandos avançavam "indo habitar áreas próximas, previamente preparadas por meio de manejo agroflorestal, isto é, abriam várias clareiras para instalar a aldeia e as plantações, inserindo novos objetos e plantas nos novos territórios" especialmente "espécies úteis para vários fins (alimentação, remédios, matérias-primas)".

Susnik (1979/80) considerou também que as grandes migrações podem ter sido originadas a partir da procura por áreas propícias para as práticas agrícolas e a caça, protótipos culturais de todos os povos de cultura no neolítico tropical. Avançavam sobre novos domínios abrindo clarões na floresta com o corte e a queima da mata para estabelecer aldeias e fazer suas roças (NOELLI, 2004). Salienta-se que essa posse de novos territórios guarani também pressupunha a sua imposição sobre outros grupos humanos (RIBEIRO, 1996; SOARES, 1997). Ao escolherem áreas da Mata Atlântica e da floresta pluvial tropical foram expandindo seus domínios por boa parte do território que atualmente figura o atual estado do Paraná. Uma vasta população de índios falantes de uma mesma língua ocupava toda a região norte e oeste do estado paranaense, terras adjacentes aos vales de grandes rios como Paraná, Paranapanema e Iguaçu, além do planalto curitibano e extensa faixa litorânea que se estende para os outros estados do Sul e Sudeste. Estima-se que no início do século XVI os guarani experimentavam um cume demográfico e geográfico (NOELLI, 2004) e que Meliá (1997) julgou em 1,5milhão o contingente de pessoas vivendo no início do século XVII na extinta Provincia del Guayrá, que abarca atualmente parte do estado paranaense.

Esses guarani históricos sofreram redução demográfica imensa decorrente dos processos brutais de colonização, desterritorialização e dispersão nos séculos que seguiram à invasão e conquista europeia. Uma boa parte da população paraguaia mais antiga resultou da mestiçagem biológica dos guarani históricos, bem como parte da população litorânea do Brasil (MONTEIRO, 2006). Ainda no século XVII, remanescentes guarani reduzidos pelos jesuítas se incorporaram às populações já mestiças do Paraguai, Argentina e do Rio Grande do Sul (CHAMORRO, 2008). Sem possibilidade de precisar o número, supõe-se, no entanto, que ao longo dos séculos XVI, XVII e XVIII alguns grupos falantes do guarani teriam se refugiado em locais inacessíveis, permanecendo isolados até meados do século XIX (CLASTRES, 1978). Esses grupos que teriam permanecido escondidos nas matas próximas ao rio Paraná e nas cordilheiras do Amambai e Maracaju, no Paraguai, a partir do século XVIII receberam a denominação genérica de ka'ayguá com diversas corruptelas fonéticas e variantes ortográficas, mas mantendo um sentido mais amplo de pessoas que 
habitam as matas (CADOGAN, 1997; CLASTRES, 1978; CHAMORRO, 2008). Destes, descenderiam os atuais mbya, xiripá e paim, segundo Hélène Clastres (1978).

Certamente, há uma imprecisão no emprego da denominação guarani para uma variedade enorme de índios que foram contatados pelos europeus desde o início do século XVI. Apesar da vasta literatura, alguns autores afirmam que há uma distância entre os guarani descritos nas etnografias e os guarani históricos provocada pela lacuna no conhecimento específico anterior à conquista do continente pelos europeus e no decorrer dos primeiros séculos de colonização. Para Monteiro (2006), isso remete a um problema metodológico quando se pretende inferir determinados aspectos dos guarani históricos a partir das etnografias contemporâneas.

Se durante a fase do colonialismo hispânico houve redução dos índios e suas particularidades, os monteses, kaynguá ou kaaguá que se refugiaram nas montanhas foram igualmente de alguma maneira todos conceitualmente reduzidos, chegou a afirmar Meliá (2004). Após as independências do Brasil, Paraguai e Argentina já avançando para os séculos XIX e XX, o autor pondera que diferentes etnias guarani - ou não - dispersas outrora, foram forçosamente reagrupadas a despeito de suas diferenças dialetais e rituais (MELIÁ, 2004).

Quando o antropólogo Egon Schaden (1974), na década de 1950, propôs uma subdivisão para as parcialidades étnicas guarani do Brasil, ele localizou hordas mbua ${ }^{2}$ no oeste do Paraná, território de Guaíra e leste paraguaio. Localizou ainda os ñandeva que se autodenominavam dessa forma e que segundo Schaden eram chamados pelos mbua de xiripa'i. Schaden (1974), baseado nos dados de Curt Nimuendajú, registrou ondas migratórias nas décadas de 1920, 1930 e 1940 também originárias do leste paraguaio e nordeste argentino atravessando o Rio Grande do Sul, Santa Catarina e Paraná com a finalidade de atingir o litoral paulista. Segundo Schaden (1974), os ñandeva seriam apapokúva ou avákatu - aqueles pesquisados por Curt Nimuendajú no início do século passado e que viviam na época no extremo sul do Mato Grosso, fronteira com Paraguai e próximos ao Paraná. Os ñandeva ocupariam ainda faixas contíguas aos rios Iguatemi, no Mato Grosso, e a serra de Maracaju, no Paraguai, até chegar ao rio Acaray, estendendo-se pelas margens dos rios Iguaçu e Paraná em direção ao leste até atingir os rios Ivaí, Piquiri, Tibagi e Paranapanema.

A classificação proposta por Egon Schaden tem sido adotada consensualmente na etnologia guarani e está baseada em diferenças linguísticas, de cultura material e nas práticas rituais. Essa literatura etnográfica clássica divide os guarani que vivem no Brasil em três parcialidades étnicas: os kaiowá, ñandeva e mbya.

\footnotetext{
${ }^{2}$ Manteve-se aqui a grafia utilizada por Egon Schaden (1974) para se referir aos mbya.
} 
Ladeira $(2007,2008)$ fez uma breve revisão dos etnônimos guarani e mbya distinguindo-os bem das autodenominações, como também das denominações utilizadas entre os grupos para se referirem à alteridade. Salientou que muitas denominações, na maioria das vezes, empregavam qualificativos considerados pejorativos e não aceitos pelo grupo.

Já Mello (2007) faz uma revisão crítica da classificação proposta por Schaden (1974) e aponta que os xiripa foram equivocadamente subsumidos entre os mbya ou confundidos com os ñandeva. Na sua tese de doutorado, a autora analisa as redes de parentesco e deslocamentos em Santa Catarina, e observa a coabitação histórica entre mbya e xiripa e o grande intercurso matrimonial entre as etnias (MELLO, 2006).

Mello (2007) aponta que mbya, autodenominação tambeopé, também é utilizada como autodenominação inclusiva pelos paim e xiripa diante dos brancos. O etnônimo mbya tem sido usado de forma mais ampla pelas autodenominações inclusivas paim, tambeopé e xiripa, especialmente nas interações com a sociedade nacional, por entenderem ser esta uma categoria que representa para os nãoindígenas um sinônimo de guarani autêntico (MELLO, 2007). Já os ñandeva são identificados em Santa Catarina como índios do Paraná falantes de uma língua diferente, não compreendida pelos grupos mbya e xiripa desse estado.

Na região oeste do estado do Paraná, os ñandeva também eram referidos pelos mbya e xiripa como índios "de tipo diferente", especialmente no que tange à língua, entretanto, ali os mbya mantinham com aqueles alianças políticas e matrimoniais constantes. Alguns mbya se autodenominavam paim e outros tambeopé, apesar de se afirmarem como grupo homogêneo mbya diante dos ñandeva. Nota-se que a despeito das pressões territoriais provocadas pelo avanço das frentes de colonização para o oeste que impeliram os diferentes grupos a coabitarem em uma mesma área, as relações postas em movimento são multilaterais e envolvem dois pontos a serem considerados.

O primeiro toca nas relações com o exterior e o homem branco. Há uma tendência em um primeiro momento, na relação com os brancos, em se identificar como um grupo monolítico e homogêneo. O cacique da área indígena de Itamarã (localizada no oeste paranaense), como forma de contentar as expectativas das diferentes famílias residentes na área, quando falava aos brancos representava em tom uníssono os guarani. Contudo, houve tempo em que a aldeia teve um cacique oriundo de uma família local ñandeva e, que na opinião de algumas pessoas mbya, erroneamente a aldeia era na época associada à etnia com a qual o cacique se identificava. Na pesquisa de campo, acompanhei também uma família xiripa advinda do Paraguai. Logo que se instalaram no Brasil, essas pessoas passaram a se identificar como mbya, pois diziam ser um tipo de guarani desconhecido na região. Para facilitar seu reconhecimento, apresentavam-se como mbya, que era 
mais conhecido, e argumentavam que seus costumes e língua se aproximavam dos mbya. Diziam ainda que essa forma de identificação não gerava problemas com autoridades brasileiras, que poderiam questionar a entrada de índios paraguaios em áreas indígenas localizadas no Brasil. Uma liderança local, e um de meus principais informantes, relatou que para alguns grupos após processos históricos de coabitação e alianças, a identificação mbya às vezes era acionada estrategicamente para receber um estatuto de guarani puro. Certa vez, disse-me que ao contrário dos índios da Amazônia, que ninguém duvidava que seu lugar original fosse a floresta, os guarani não gozavam de muita simpatia na região e geralmente eram vistos como índios estrangeiros invasores do território ocupado pelos migrantes sulistas.

O segundo ponto diz respeito ao fato que a coabitação entre diferentes etnias amalgama uma complexa rede de alianças, intercursos matrimoniais e reciprocidade que engendra uma dinâmica própria à aldeia. Uma instabilidade profusa dissimula-se no interior da vida social local e daí decorre a sua invariável movimentação, uma busca inesgotável, nunca definitiva, de alianças para a efetivação de um socius que seja considerado teko'a porã (um lugar perfeito), um espaço propício para o modo guarani de viver como comunidade de parentes (retarã).

Nas aldeias de Itamarã e Añetete em que realizei a etnografia e vivem as principais lideranças entrevistadas nesta pesquisa, habitam famílias que se autodenominam mbya, outras famílias que se autodenominam ñandeva e núcleos familiares que se autodenominam xiripa. Muitas famílias migraram do leste paraguaio, nordeste argentino, província de Missiones ou são provenientes de áreas do extremo oeste paranaense, mais especificamente de ocupações territoriais históricas nos atuais municípios de Foz do Iguaçu, Toledo, Marechal Cândido Rondon, Cascavel e Guaíra, conforme as áreas que são identificadas adiante no Quadro 1.

\begin{tabular}{|l|c|c|}
\hline Municípios & Aldeias & Número aproximado de famílias \\
\hline Toledo & Jabuticaba & 3 \\
\hline Toledo & Tatujupi & 40 \\
\hline Toledo & Lope'i & 17 \\
\hline $\begin{array}{l}\text { Entre Toledo e Cascavel (próximo } \\
\text { ao rio Lopeí) }\end{array}$ & Mboipikuá “caverna dos morcegos” & 20 \\
\hline Toledo & Mbokae & - \\
\hline Toledo & Paraje & 15 \\
\hline Toledo & YvY u & - \\
\hline Toledo (próximo ao aeroporto) & Campina & 42 \\
\hline $\begin{array}{l}\text { Toledo (entre Toledo e Marechal } \\
\text { Cândido Rondon }\end{array}$ & Memória & - \\
\hline $\begin{array}{l}\text { Toledo (entre aldeias Campina e } \\
\text { Memória) }\end{array}$ & Britador & \\
\hline
\end{tabular}




\begin{tabular}{|l|c|c|}
\hline Corbélia & Pakova & - \\
\hline São Miguel do Iguaçu & Três Irmãs & - \\
\hline São Miguel do Iguaçu & Quatro Pontes & - \\
\hline Quatro Pontes & Porto Britânia & - \\
\hline $\begin{array}{l}\text { Marechal Cândido Rondon (distrito } \\
\text { Porto Mendes) }\end{array}$ & Guavirova (submersa) & - \\
\hline Alvorada do Iguaçu & Aldeia do rio Takuapindaí (submersa pelo Lago & \\
\hline Alvorada do Iguaçu & Aldeia do rio Mborevy (submersa pelo Lago de & \\
\hline Alvorada do Iguaçu & Itaipu) & - \\
\hline Alvorada do Iguaçu & Jakutinga (submersa pelo Lago de Itaipu) & \\
\hline Alvorada do Iguaçu & Ipiranga (submersa pelo Lago de Itaipu) & \\
\hline Alvorada do Iguaçu & Passo Kuê (submersa pelo Lago de Itaipu) & - \\
\hline Alvorada do Iguaçu & Aldeia do rio Mboyci (submersa pelo Lago de & - \\
\hline Matelândia & Itaipu) & - \\
\hline Foz do Iguaçu & Ko'eju “o amanhecer” & - \\
\hline
\end{tabular}

Quadro 1 - Aldeias anteriores a 1940 no oeste do Paraná.

Fonte: GIORDANI, 2010, adaptado de RIBEIRO, 2002.

A mobilidade e os deslocamentos entre aldeias são a tônica desse grupo e marcam uma certa circularidade nos deslocamentos atuais a partir de um território básico. Assim, a crescente presença dos guarani na região assemelha-se a um processo descrito por Darella (2004, p.92) como reguaranização do espaço, expressão de um "território-de-e-em-movimento" formado por uma rede de aldeias substantivadas em parentesco, afinidade, intercâmbio e reciprocidade.

Entre os que ficaram por algum tempo em áreas indígenas criadas ao longo dos últimos anos e aqueles que se deslocaram para lugares onde tinham parentes, fez-se o tempo socialmente constituído de retornar. Tupã Jeguavy, um mbya muito envolvido nas negociações políticas com as agências governamentais e na luta por terra afirmou diversas vezes que agora era "o tempo dos guarani pegarem suas terras de volta". O movimento para a reconquista dos seus antigos territórios e que produz efeitos criadores de alianças e casamentos entre mbya e ñandeva, produzindo mais índios guarani, traz também de longe outros parentes ou parentes potenciais, como os xiripa, que vêm se deslocando gradativamente do Paraguai. Tupã afirmava que muitos vinham ocupar a terra exatamente naquele sentido dado por Darella (2004) de reguaranizar o espaço. 


\section{A chegada de muitos ou sobre os conquistadores contemporâneos}

Após a Guerra do Paraguai no segundo quartel do século XIX, os guarani permaneceram relativamente isolados em grandes porções de terras no Paraguai até meados do século XX, quando imensas áreas para exploração de erva-mate foram entregues às empresas pelo governo paraguaio (CHAMORRO, 2008). A Guerra do Paraguai também teve repercussões imediatas sobre terras indígenas nativas localizadas nas regiões atuais do oeste paranaense e mato-grossense quando o Império brasileiro decidiu implantar uma colônia militar na região fronteiriça, tendo em vista a avaliação política da exposta vulnerabilidade brasileira e a necessidade de povoar a região (COLODEL, 1993).

A atividade econômica que predominava no Paraná era o tropeirismo, que já ocupava os Campos Gerais desde o século XVIII e havia se expandido a partir do planalto curitibano. Guarapuava era a povoação mais próxima da região a ser atingida pela Comissão Estratégica e passou a ser o centro das operações que foram adentrando em direção à foz do rio Iguaçu e avançando pelo interior sobre territórios ocupados pelos índios (FREITAG, 2001). Após a instalação da Colônia Militar iniciou-se a concessão de lotes para o povoamento do extremo oeste paranaense (RIBEIRO, 2002). Muitos índios denominados pelos militares como cayuás eram contatados, catequizados e serviram de mão de obra para os trabalhos da Comissão na região. Lentamente, as adjacências da foz do rio Iguaçu foram sendo ocupadas pela população brasileira e alguns guarani que ainda não haviam fugido para outras regiões mata adentro foram aldeados pela Comissão Estratégica (COLODEL, 1993). Também há relatórios de cronistas, na época da fundação da Colônia, como a de José Maria de Brito, afirmando que "a costa do rio Paraná, da foz do rio Iguaçu até $72 \mathrm{~km}$ acima era ocupada, no momento da fundação, por poucos brasileiros e muitos índios estrangeiros" (CHMYZ, 1990 apud RIBEIRO, 2002, p. 136).

Da mesma forma que ocorrera no Paraguai, também imensas áreas de mata nativa em território brasileiro ocupadas tradicionalmente pelos guarani eram exploradas exaustivamente por empresas mateiras e madeireiras, especialmente argentinas e inglesas, que dominavam o comércio e navegavam pelos rios da bacia platina formando as obrages ${ }^{3}$ (FREITAG, 2001; GRONDIN, 2007). A grande maioria dos trabalhadores recrutados era formada pela população paraguaia, os mensus (WACHOWICZ, 1982), entretanto, essa atividade, que perduraria até meados da década de 1940, também recrutou muitos índios guarani, como comprovou mais tarde o arqueólogo Igor Chmyz, da Universidade Federal do Paraná, através do Projeto Arqueológico Itaipu (RIBEIRO, 2002).

\footnotetext{
${ }^{3}$ Termo regional que se refere às grandes propriedades rurais formadas no oeste paranaense em que se estruturaram formas específicas de dominação e exploração do trabalho (COLODEL, 1988; WACHOWICZ, 1982).
} 
A respeito da ocupação territorial guarani, Darella (2004) faz importantes considerações sobre a dinâmica demográfica e geográfica guarani e a variação nos modos de ocupação em diferentes regiões de domínio da Mata Atlântica ao longo dos períodos que sucederam a ocupação europeia no século XVI. Darella considera a hipótese de uma “dispersão forçada ou estratégica” por meio de deslocamentos para faixas de mata atlântica de difícil acesso apoiando-se parcialmente em dados da evolução histórica das formações florestais nos estados de Santa Catarina e Paraná entre os séculos XVI e início do século XX. Avalia a autora que:

[...] em termos de cobertura florestal natural em relação a sua área total, [...] incide a cobertura de $84,72 \%$ e $83,37 \%$ [...]. Ocorre, portanto, elevada preservação florestal nesses dois estados entre os séculos XVI e XX, em contraposição ao período 1912 a 1995 , com [...] 83,37\% e 8,93\% de cobertura florestal [...] no Paraná, indicando acentuada devastação florestal em 83 anos (DARELLA, 2004, p.83).

A propósito das transformações acentuadas no espaço social guarani que foram vivenciadas pelo grupo atual ou de uma experiência que perdura através da memória dos guarani mais velhos que residem em áreas indígenas na região, essa análise aporta informações complementares ao cenário desenvolvimentista que se consolidou na região.

A exploração madeireira continuada deflagrou a devastação de grande parte das florestas de araucária da região oeste do Paraná. Somada ao crescente povoamento das regiões mais interioranas pelas frentes colonizadoras que avançavam sobre o território indígena, sobretudo a partir da década de 1930, foram enfim encurralados progressivamente os guarani que viviam embrenhados nas florestas da região.

$\mathrm{Na}$ perspectiva da política federal do governo Getúlio Vargas de integrar e articular as diferentes regiões do país, delineou-se uma política territorial que "[...] traçou um modelo da sociedade legítima, irmanada em uma só língua e tradições, identificando a ocupação do espaço nacional, como um movimento integrador" (FREITAG, 2001, p. 44). A Marcha para o Oeste teve um significado expansionista para o extremo oeste do estado, pois até então a região era percebida como um "vazio da nacionalidade" que conjugava diferentes etnias e outras nacionalidades que não incluíam o gentílico brasileiro (FREITAG, 2001, p. 67). Certamente os guarani que habitavam as cercanias dos povoados também foram identificados pelo gentílico "paraguaios" e tiveram sua circulação reprimida. Nesse contexto histórico, algumas empresas colonizadoras puseram em prática "uma política colonizatória voltada a um determinado contingente populacional, no caso migrantes ítalo e teuto-brasileiros" (SCHENEIDER, 2000) e a posterior formação de uma economia baseada na agricultura familiar e pequena propriedade (SANTOS, 2001). 
A Industrial Madeireira Colonizadora Rio Paraná S/A, Companhia Maripá, foi uma dentre várias empresas que teve papel importante nesse contexto histórico regional, levando colonizadores italianos e alemães provenientes dos estados do Rio Grande do Sul e Santa Catarina para o oeste paranaense (RIBEIRO, 2002). No bojo desse movimento, havia segundo Mota (2009) a ideia de um "vazio demográfico" (MOTA, 2009), de terras selváticas, devolutas, e à disposição do Estado para serem ocupadas e desenvolvidas. Na década de 1960 algumas colônias fundadas pelas frentes de colonização da região oeste já acumulavam um contingente populacional de 60.000 habitantes (GRONDIN, 2007). Muitas dessas áreas que comportavam locais habitados pelos guarani (ver Quadro 1) e notadamente identificadas pela topografia foram incorporadas pelos colonizadores às cidades formadas.

A despeito das ideias correntes na época de que os campos oestinos seriam áreas desocupadas a serem conquistadas e alguns documentos oficiais e relatórios das colonizadoras indicarem apenas de forma esparsa e imprecisa a presença de índios, confronta-se a memória dos guarani mais velhos que protagonizaram de maneira dramática os contatos com os brancos. Alguns guardam a memória do grupo e indicam precisamente a ocupação pretérita da região desde pelo menos o início do século XX. Haveria aldeias históricas se espalhando em uma área contígua dos rios Paraná, Iguaçu e seus afluentes.

Análises documentais de Ribeiro (2002, p. 137) indicam que o expansionismo e a intensificação dos povoamentos em direção ao oeste do Paraná foram progressivamente restringindo as áreas de circulação dos ñandeva e mbya, delimitando sua circulação em aldeias às margens do rio Paraná, dos rios Jakutinga, Ocoy, Guaxirõ, Guaxirõ'y, Bela Vista, Pirito, Passo Kuê e Porto Irene.

No período que precede a moderna colonização propriamente dita com a formação dos povoados, a extração da madeira entre os anos de 1946 a 1949 foi o princípio econômico que movimentou algumas colonizadoras, em especial a Maripá. A madeira era cortada e carregada até o Porto Britânia para atingir o mercado platino através do rio Paraná, contando essencialmente com a mão de obra de índios mbya e ñandeva que habitavam em aldeias adjacentes. A partir do desenvolvimento mais contundente dos núcleos de colonização e instauração de modelos agrícolas e de pequena propriedade nas barrancas do rio Paraná em que se engajavam os colonos teuto e ítalo-brasileiros, desapareciam essas obrages modernas de exploração madeireira (WACHOWICZ, 1982). Ribeiro (2002) faz nota de que a despeito da presença das obrages, os guarani permaneciam na região transitando nos seus domínios de território tradicional dentro das possibilidades que o contato permitia. A esse respeito, o xamã Karai Poty de Itamarã relatou que era muito comum se 
envolverem de acordo com seus interesses no trabalho oferecido pelas madeireiras por períodos determinados, retornando para a aldeia após algum tempo.

Com o advento dos núcleos de colonos sulistas, que eram cuidadosamente escolhidos por critérios étnicos (SCHNEIDER, 2000) e atraídos para a região, a preocupação das companhias colonizadoras passou a ser a obliteração da presença indígena nas terras oestinas. $\mathrm{O}$ governo contribuiu sobremaneira se incumbindo da tarefa de transferir índios ñandeva e mbya guarani para outras regiões como, por exemplo, para as áreas indígenas de Inácio Martins e Rio das Cobras em Laranjeiras do Sul, no centro sul do Paraná, onde índios kaingang já estavam aldeados. Muitos ainda se deslocaram para o interior das florestas em recônditos ainda não explorados e sem a presença do branco, especialmente no lado esquerdo do rio Paraná, leste do Paraguai.

Obtive informações bastante precisas de dois guarani com relação a esse assunto. O velho xamã mbya Karai Poty, que nasceu na região atualmente pertencente ao município de Toledo e que acompanhou a chegada dos colonos, o processo de ocupação e formação das primeiras vilas, relatou que viveu muito tempo entre os brancos, trabalhando na exploração madeireira pela Companhia Mate Laranjeiras, para a colonizadora Maripá. Um dado interessante relatado pelo mbya são os anos de convívio com a família de Willy Barth, na época o presidente da Companhia Maripá, principal agente civilizadora do oeste. Karai Poty trabalhou diretamente na residência do então presidente, ali permanecendo por muitos anos. Outro depoimento que obtive sobre esse período de ocupação dos brancos na região foi o relato de uma velha ñandeva da qual descendem muitos guarani que transitam entre as áreas indígenas oestinas brasileiras e o Paraguai. Ela nasceu em área próxima à Foz do Iguaçu, mas nunca viveu entre os brancos, e ao contrário do xamã bilíngue fluente tanto em mbya quanto em português, a índia ñandeva fala estritamente seu dialeto. Ela relatou constantes deslocamentos empreendidos pela sua família quando ainda era criança com objetivo de evitar o contato. Deslocamentos forçados ou fugas, lembra, eram para se refugiar no mato em decorrência do avanço da sociedade nacional.

Para o contexto regional específico, dentre as ações da sociedade nacional com maiores impactos sobre os grupos guarani que viviam até as décadas de 1940, 1950 e 1960 nas áreas contíguas da bacia do rio Paraná, a construção da Usina Hidrelétrica Itaipu Binacional teve proporções transformativas ainda não esgotadas sobre os atuais ñandeva e mbya. O projeto efetivou-se na década de 1970, abrangendo trechos do rio Paraná desde o Salto de Sete Quedas até a foz do rio Iguaçu. Mais precisamente em 1975, iniciaram-se as obras de construção e já em 1982 estava concluída quando as comportas do canal de desvio foram fechadas, represando a água e formando o reservatório do Lago de Itaipu, encobrindo uma extensão de 1.350 quilômetros quadrados e várias áreas ocupadas pelos guarani. 


\section{Em busca de terra}

A história das famílias etnografadas nesta pesquisa que hoje ocupam a região oeste do estado do Paraná "é uma história de lutas e permanências", definiu a liderança mbya Tupã Jeguavy já em nossas primeiras conversas sobre a trajetória de seu grupo. Muitas famílias são remanescentes da antiga aldeia Jakutinga, território que foi alagado após o represamento do trecho do rio Paraná entre Salto Del Guayrá e a foz do rio Iguaçu. O número de famílias que viviam na região não é preciso, mas alguns guarani mais velhos originários do grupo inicial que residiam na Jakutinga estimam cerca de 150. Majoritariamente formado por famílias ñandeva, índios relataram que a Jakutinga resultou dos deslocamentos de famílias guarani pressionadas pelo avanço dos colonizadores. Ribeiro (2002) igualmente registrou esse fato que muitos guarani, buscando áreas livres da presença dos colonos sulistas, refugiaram-se e se instalaram nas margens do rio Paraná e bordas de seus afluentes, constituindo um lugar identificado já na década de 1960 como Teko'a Jakutinga.

No início da década de 1970 também se iniciou uma intensa dispersão desencadeada pelas visitas constantes dos técnicos do Instituto Nacional de Colonização e Reforma Agrária (Incra) para a avaliação da área como possível local para assentar colonos provenientes do Parque Nacional do Iguaçu (RIBEIRO, 2002). Um guarani remanescente daquele grupo relembra que muitas famílias ñandeva e mbya fugiram para o Paraguai acuadas pelos métodos que o Instituto utilizou para expulsá-los. Pequenos grupos foram se refugiar em áreas de floresta no outro lado do rio Paraná onde permaneceram muitos anos.

A década de 1970 foi marcada pelo acirramento dos mecanismos de pressão contra os grupos nativos da região. Em 1977, a Comissão XV instituída pela Fundação Nacional do Índio (Funai) e pelo Incra foi encarregada de "avaliar a indianidade" de grupos que habitavam a área e comprovar a presença dos guarani (RIBEIRO, 2002). Apesar de percorrerem "duas pequenas faixas de terra", segundo relato coletado nesta pesquisa, a comissão afirmou a inexistência de índios em área localizada no município de Foz do Iguaçu e pontuou a presença de onze famílias na terra que futuramente seria alagada pelo represamento das águas da barragem da Usina Hidrelétrica Itaipu.

Em Itamarã, fala-se que apesar da reivindicação de 1500 hectares referentes aos seus domínios que se estendiam desde o rio Jakutinga seguindo o rio Ocoy até Santa Helena e finalmente chegando às margens do rio Paraná no teko'a Guasu, a Itaipu, a partir de um relatório encomendado, tendo a Funai como partícipe, conclui que seriam necessários 265 hectares para assentar as 11 famílias guarani. Em depoimento à historiadora Sarah Ribeiro em 2000, o velho pajé que liderava o grupo na época conta sobre o ano de 1982, quando os índios foram deslocados sem 
prévio conhecimento de seu destino para um lugar que compreendia 251,15 hectares oficialmente demarcados no município de São Miguel, o Tekóa Ocoy. Apenas após a chegada teriam sido notificados de que o local onde residiam anteriormente, a Jakutinga, seria em breve submerso pela construção da usina.

Nessa nova área, padrões alimentares associados à cultura guarani não podiam ser praticados dada a exiguidade de terras agricultáveis, a parca cobertura vegetal, além da piscosidade afetada pelos dejetos agrícolas, motivando o grupo a buscar outro local para viver. Um movimento indígena passa então a se constituir e se organizar para constantemente reclamar providências na usina e a Funai reiterando os direitos do grupo sobre uma área condizente aos 1.500 hectares da Jakutinga.

Nota-se que após a demarcação de Ocoy, muitas famílias nucleares que haviam partido para aldeias espalhadas ao longo do seu território original retornaram para junto de seus parentes aldeados. Índios guarani que nasceram na antiga área Jakutinga fugidos dos confrontos violentos com brancos em Foz do Iguaçu e que haviam permanecido por anos em aldeias no Paraguai retornam causando uma dilatação demográfica expressiva. Somado aos problemas anteriores relativos à sustentabilidade alimentar, os 250 hectares passaram a ser insuficientes para prover materialmente todos os moradores do Ocoy. Uma parte do grupo permaneceu ali somente entre 1981 até 1995 e depois capitaneados pelos irmãos ñandeva Centurião, além dos mbya Tupã Jeguavy e Karai Poty, iniciam uma luta por ampliação de territórios na região.

Ao longo da década de 1980 esse grupo fez reiteradas reivindicações que, todavia, não foram levadas a efeito pelos aparelhos estatais responsáveis pelo litígio. Entretanto, a renitência dos órgãos envolvidos e a condição dos índios naquele momento começou a ganhar certa projeção nacional, quando organizações não governamentais ambientalistas e de defesa de direitos humanos, a imprensa e o Ministério Público Federal, por meio de ação civil pública, passaram a se engajar politicamente na demarcação de terra na região.

No ano de 1992, a Hidrelétrica Itaipu aquiesce outorgar os 1.500 hectares, em um aceno da usina diante do recrudescimento das pressões exercidas pelo grupo. No período, eles chegaram a ocupar uma área destinada à Reserva Legal da Hidrelétrica, onde ficaram por quase 4anos até que sob os auspícios financeiros dela, em dezembro de 1997 foi adquirida uma área de 1.744 hectares nas confluências dos rios Falso São Francisco e São Domingos nas adjacências do município de Diamante d'Oeste, denominada Añetete.

Para os guarani, a qualidade do lugar era considerada ambígua. Se por um lado abrangia uma boa extensão territorial com matas que ofereciam algumas plantas de uso ritual, material para construção de casas e cestarias, de outro o solo foi considerado excessivamente pedregoso, além da 
ausência de nascentes de rios. Isso gerou incertezas sobre a mudança em algumas famílias que preferiram permanecer no Ocoy (RIBEIRO, 2002), entre elas as famílias de Tupã Jeguavy.

Em Ocoy as dificuldades só cresciam, assim como os ânimos propiciadores para buscar novas condições de existência. Da terra que os "consumia", como me explicou certa vez um dos mbya, aumentava no grupo de famílias o desejo de viver conforme seus costumes. Ansiavam pela terra que estavam convencidos que lhes pertencia. Uma terra "prometida", para ser mais fiel com o que me disseram.

Karai Poty, Tupã Jeguavy com a mulher e filhos, o velho ñandeva Teodoro Centurião, seus filhos e netos iniciam uma peregrinação com várias paradas em diferentes locais, todos circunscritos na região do extremo oeste. Partiram essas famílias de São Miguel do Iguaçu em direção ao município de Terra Roxa, área em que, segundo diziam os velhos guarani, haveriam indícios de cemitérios e ruínas das antigas reduções jesuíticas. Não obtiveram êxito na demarcação de terras nas cercanias desse município e depois de muitas idas e vindas entre aldeias e acampamentos na região, ocuparam porções de terras adjacentes à aldeia Añetete. Permaneceram ali por um ano até que finalmente a situação foi regularizada. A área comprada pela Funai no ano de 2007, chamada Itamarã, é uma clareira na floresta secundária e capoeira da região, situando-se em um vale rochoso entre os municípios de Diamante do Oeste e Vera Cruz do Oeste. Fixaram-se ali parte do grupo que peregrinava junto há vários anos e outras famílias originárias do Paraguai que vêm se estabelecendo na área a partir de alianças matrimoniais com cônjuges pertencentes às famílias extensas que exercem liderança política e religiosa na aldeia.

\section{YvyMara'e y, A Terra sem Mal e YvyVa'e, A Terra que consome}

Terra Sagrada - é assim que Tupã Jeguavy, um dos líderes do grupo, narra o lugar para onde os guarani se orientam. Um lugar que se persegue, no sentido de uma utopia como me definiu: "Os guarani estão sempre na busca do teko'a porã” (lugar bom ou perfeito). Na sua análise, se porã qualifica aquilo que a divindade Ñanderu ete'i (Nosso Pai Verdadeiro) deixou para os verdadeiros humanos é, portanto, um lugar que tem a conotação de original e legítimo guarani. Por outro lado, Teodoro me explicou que é a conquista de um lugar sonhado, desejado ou alcançado que se faz porã a partir de uma moralidade experimentada e cultivada no modo de ser da etnia: "Nós sabemos que a terra boa mesmo está difícil, mas tem que buscar o lugar e fazer nele a vida do jeito guarani”. O tema remete a uma conquista visível quando determinados locais passam a ser almejados, como no caso dos mbya, que lutam por territórios no sudeste paulista relatado por Ladeira $(2007,2008)$, ou 
mesmo ilustra a história desses grupos que dizem ser donos legítimos de terras hoje "cobertas pelo cimento", segundo Tupã Jeguavy. Igualmente, essa busca pela terra é no limite um devir ou uma utopia que às vezes ele explicava como um desejo que persegue e move o homem e a mulher guarani.

Yvy Mara'e y é um "lugar onde não tem prejudicação, é tudo de um tipo só”, me afirmou outro velho mbya. Os lugares legítimos dos guarani são descritos frequentemente como perfeitos, onde há "abundância de frutos doces", "animais fáceis para caçar", "peixes grandes em rios limpos", e os vegetais crescem graciosamente em seus roçados.

Há certa ideia de busca por lugares apropriados para se viver e a formação de um espaço ideal para a vida entre parentes, a possibilidade de suas práticas rituais, o uso da terra e toda uma sorte de desdobramentos políticos e sociais que constituem o teko'a. Se o termo teko'a pode ser utilizado simplesmente para designar a aldeia e seu espaço físico, esse sentido prosaico pode ter conotações mais amplas relacionadas à realização de um modo de ser legítimo para os guarani denominado pelo termo teko, que está profundamente relacionado à mitologia e ao tema da Terra sem Mal - Yvy Marãe'y (MELIÁ, 1990). Em Itamarã, ouvi se referirem ao teko como o exercício da vida conforme os preceitos mítico-religiosos, a realização de uma moralidade na conduta entre parentes que inclui a produção e divisão de alimentos, o cultivo de uma vida sem excessos e na manutenção da vida ritual na opy (casa de reza). Em suma, é um corpus denso de práticas e significados que expressam o que costumeiramente os guarani expressavam como ñandereko, "nosso jeito" ou "nosso costume" na tradução para o português.

Mesmo que a palavra teko'a seja utilizada para designar uma aldeia, como Teko'a Ocoy, por exemplo, pelo que compreendi a partir de meu contexto etnográfico, o sentido da palavra é vivenciado como uma comunidade de parentes (retarã) que experimentam as vivências cotidianas orientados por uma ética suprema referente à formação e à condição da pessoa. Esse sentido implica na definição e construção de uma convivialidade agradável, com desmembramentos nas esferas da produção e divisão de alimentos, na vida cerimonial e ritual, e na redistribuição de dons (ASSIS, 2006). Percebe-se nessa concepção as extensas implicações sobre uma espacialidade concreta traduzida por boas condições ecológicas e na constante reconstrução do espaço social ideal.

Uma primeira definição do teko em Vocabulário y Tesoro de La Lengua Guarani, do Padre Antonio Ruiz de Montoya (apud PISSOLATO, 2007, p. 108), no século XVII aparece como: "ser, estado de vida, condição, estar, costume, lei, hábito”. Esses significados parecem ainda ressoar nas narrativas guarani contemporâneas sobre a noção daquilo que se procura exercitar diante das circunstâncias de um mundo guarani em constante relação e troca com o exterior e o mundo dos brancos. Percebo, a saber, entre os guarani com os quais convivi, que a categoria teko'a, na 
perspectiva do pensamento nativo, é uma proposição que se põe em relação o tempo todo com eventos e circunstâncias. E quando há desequilíbrios nas formas adequadas da vida autóctone, em acordo com Pissolato (2007, p. 119), ativa-se um ethos buscador, uma moral que os impulsiona a procurar novas possibilidades de existência.

De outro lado, muitas narrativas a respeito de lugares sagrados remetem aos antigos teko'a localizados no espaço e no tempo mítico. Essas histórias da oguataporã (oguata - caminhada, porã belo, e que tem ainda a conotação de sagrado), são contadas por diferentes narradores, apresentando inclusive nomes de diferentes lugares sagrados criados pela divindade.

Em Itamarã, tomando por base exclusiva os depoimentos que colhi em campo, particularmente se destacaria uma busca menos orientada pela cataclismologia e a busca de uma Terra sem Mal em direção ao leste (CLASTRES, 1978; LADEIRA, 2007, 2008) que a preocupação pela reocupação de territórios localizados em uma extensa região contígua à bacia dos rios Paraná e Iguaçu. Como afirmou Ribeiro (2002), o horizonte de busca para esses grupos contemporâneos também pode ser a terra que lhes foi tomada (RIBEIRO, 2002) quando atualizam um conhecimento antigo de seus ancestrais e que se interpõe entre o mito dos guarani como seres especiais criados pela divindade para habitarem teko'afundados em tempos míticos e os processos históricos mais amplos desencadeados pelas relações de contato.

Convictos de que essas moradas outrora habitadas podem ainda ser buscadas e conquistadas, perseguem esses territórios. A permanência do guarani no mundo atual, que denominam imperfeito, é uma agência contínua que, se de um lado depende dos cuidados diários para a produção de um estado de ânimo apropriado e uma ênfase nas relações entre parentes, de outro é alimentada pela disposição em "seguir". "O meu sonho é ir construindo teko'a e povoar o mundo com mais guarani”, me afirmava sempre Tupã Jeguavy.

A busca por novas condições de vida tem uma conotação especial dentro do pensamento guarani. É diante de novas oportunidades, da mudança dos contextos de existência que os deslocamentos podem ser construídos dentro de um território que extrapola as possibilidades dos aldeamentos atuais. Essa disposição por uma vida de qualidade diferente, no entanto, é um sentimento que se compartilha entre os iguais e pode colocar em movimento o ânimo da coletividade inteira.

Essa etnografia sugere que na história protagonizada pelas famílias que vivem em Itamarã, Añetete e Ocoy, a falta de satisfação quando o que se procura é estar bem (ikoporã), e estar alegre (vy’a), assumiu um papel central na confluência entre um sentimento coletivo de caos e tristeza e a possibilidade derradeira de reocupar antigas áreas. $\mathrm{O}$ auge desse sentimento parece ter ocorrido no confinamento do grupo em Ocoy e na sucessão de lutas por território desencadeadas pelas 
perturbações geradas pela construção da usina hidrelétrica. Além da falta de terras para plantar e a atividade da caça, os estados de ânimo produzidos pela falta de coesão, sentida especialmente quando "os parentes passam a não agir como parentes", por eventos individuais que podem ser perigosos para o coletivo, como a morte violenta de parentes ${ }^{4}$, foram sendo interpretados atentamente como fortes indicativos do tempo da mudança.

\section{Oguata - Caminhar sempre}

À época dos contatos na região oeste mais intensos e sistemáticos com a sociedade nacional, notadamente a partir da década de 1930/1940, os relatos que registrei parecem indicar traços importantes de uma organização sociológica absolutamente espalhada e estendida ao longo de uma série de aldeias interligadas sociopoliticamente e por laços de parentesco.

Essa rede atomizada e dispersa unia aldeias grandes e pequenas e as visitas entre parentes realizavam a forma por excelência de comunicação. Mesmo não sabendo precisar o número de famílias, muitos guarani indicaram que a região de Foz do Iguaçu antes da colonização mais intensa, por exemplo, abrigava um conjunto de aldeias envolvidas em uma rota circular que engendrava laços de parentesco e alianças políticas com outras aldeias localizadas em áreas atualmente pertencentes aos municípios de Toledo e Santa Helena. De um lado, certas áreas plenamente dominadas não guardavam um significado autóctone de aldeia e alguns locais entre Toledo e Santa Helena, por exemplo, tinham a função de abrigos provisórios para viagens mais longas. Parece-me que amplos trajetos que necessitavam de parada temporária poderiam imprimir certas características às novas áreas desbravadas - como roças para cultivares mais precoces; mas também poderiam contar com a hospedagem em casas de parentes ou reativar antigas áreas localizadas em sítios maiores. Tupã Jeguavy, por exemplo, aventou a possibilidade de "paradas para descanso" que poderiam durar em torno de seis meses e de alguma possibilidade das saídas com características exploratórias e para caçadas que duravam meses. Na região de Toledo e Cascavel, os rios São Francisco e Lopeí eram tradicionalmente utilizados para a pesca, além de áreas dominadas de seu entorno fornecerem excelentes pontos para caça. Ainda nesses locais a coleta de frutos, e sobretudo o pinhão, que é muito apreciado na culinária guarani, contribuía significativamente nas dietas. As saídas desses locais não implicavam, todavia, no abandono das residências, tendo a

\footnotetext{
${ }^{4}$ Os atropelamentos são bastante comuns em vias urbanas e rodovias que cortam aldeias.
} 
perspectiva de que o bando retornaria e também não ser o grupo inteiro que partia. As roças eram cuidadas pelos remanescentes que se encarregavam da labuta diária e da ocupação do local.

A mobilidade entre aldeias poderia, então, ser alimentada por uma série de fatores que compreendiam desde a busca livre para dominar novas áreas, tendo, ou não, uma conotação mais ou menos exploratória em relação ao meio, propiciando alternativas concernentes à caça e ao forrageio. Cumpriria ainda um papel em nível de uma ética da convivialidade, da visitação entre parentes para intercâmbios alimentares e trocas de sementes, além de novos arranjos matrimoniais. Para Karai Poty, a prática da oguata (caminhada), seja ela dirigida ou não à casa de parentes, era a possibilidade primeira e fundadora de uma organização multilocal que promovia a importância do parentesco nas trocas e circulação de objetos e alimentos, aventava futuros casamentos, ativava alianças políticas e ventilava informações.

$\mathrm{Na}$ opinião dos participantes da pesquisa, se os guarani contemporâneos estão aldeados em pequenas áreas, desconfigurando um território original, agora recortado e diminuído, a circulação de pessoas entre diferentes lugares permanece como uma prática cultural constante do grupo. É como se os lugares pertencessem aos guarani, mas os guarani não pertencessem aos lugares, disseram-me. O desejo de viajar, passear ou mudar de aldeia pode ser ativado a qualquer momento com ou sem motivo explícito. A visita de parentes, o desejo de conhecer uma criança que acaba de nascer ou a possibilidade de encontrar um parceiro para casar são razões que facilmente parecem inspirar os guarani para se deslocarem de onde quer que estejam e para onde quer que se dirijam. Se os velhos contaram de tempos, antes da vinda dos colonos do Sul, em que podiam se deslocar intensamente, os guarani da geração seguinte, notadamente os jovens, não parecem fazer outra coisa que circular.

Atualmente, a mobilidade e as relações de troca evidenciam-se entre aldeias da região. Entre meus registros, as viagens mais corriqueiras eram para São Miguel, Palmeirinha, Foz do Iguaçu e Nova Laranjeiras. Até mesmo longas estadias em Añetete eram comumente empreendidas pelas mulheres que eram hospedadas com seus filhos pelos parentes do outro lado da parca faixa de mata que separa as duas aldeias.A circulação de pessoas parece gerar e movimentar uma intensa rede de trocas de objetos e de pessoas, envolvendo inclusive a circulação de alimentos e sementes como espigas de milho nativo - (avaxi ete'i - milho verdadeiro), pedaços de carnes de caça comumente trazidos de Añetete ou frutas produzidas nos quintais das casas ou colhidas no mato. As festas com uma abundância alimentar cuidadosamente preparada, via de regra contava também com a chegada de parentes.

O caso do milho avaxi ete'i (milho verdadeiro) é um forte exemplo nas etnografias guarani da rede de trocas que se amalgama no interior de uma estrutura multilocal que se espalha entre 
diferentes aldeias (ASSIS, 2006; FILIPIM, 2001; LADEIRA, 2007). Após o plantio e colheita desse milho, algumas espigas são selecionadas e separadas para serem guardadas para o replantio. No entanto, observei que nem todas as famílias possuem essas sementes nativas para cultivo e que algumas podem nem mesmo produzir esse tipo de milho com regularidade. Outras famílias, entretanto, parecem funcionar como banco de sementes, redistribuindo as espigas do milho avaxi ete'i. Como esse vegetal forma a base de diversos alimentos cotidianos e rituais guarani, ele põe igualmente pessoas em circulação que carregam consigo sementes e espigas. Em geral, pareceu-me haver certa confiança no fato de que sempre existirá alguém para prover os próximos plantios. Mesmo após sucessivos deslocamentos, quando comumente os guarani não costumam carregar muitos objetos pessoais, algumas famílias se preocupam em preservar boas espigas para o replantio seguinte na nova moradia. Estas são cuidadosamente guardadas entre seus parcos pertences pessoais e carregadas durante a mudança. Em Itamarã, havia uma índia mbya casada com um ñandeva que mantinha consigo cuidadosamente uma reserva de sementes de avaxi ete'i. Seus estoques eram continuamente abastecidos quando da visitação (po’u) à casa de sua mãe na aldeia de Palmeirinha. Dela dependiam vários roçados em Itamarã e uma produção mínima para rituais na casa de reza (opy).

Outras formas de cooperação, que não precediam de qualquer ato intencional ou planejado, davam-se de forma espontânea e iniciavam de maneira desproposital, com uma visita. Pessoas que chegavam frequentemente participavam das atividades produtivas na esfera alimentar para ajudar seus anfitriões. De outro lado, o deslocamento de jovens para casa de parentes podia compreender uma intenção mais ou menos velada de aprendizado de técnicas e de saberes através da oportunidade de convivência com pessoas dotadas de prestígio em determinadas atividades. Observei duas situações específicas entre as aldeias Itamarã e Añetete, e Itamarã e Rio das Cobras, em Laranjeiras do Sul, quando os jovens se deslocaram para esses locais e oportunamente aprenderam a caçar ou pescar. Quando estes retornavam do mato com bichos, comentavam-se suas habilidades pessoais, mas o valor de uma convivência e aprendizado anterior noutra aldeia não deixava de ser notada.

Nessa mesma lógica das conexões entre aldeias, resolver um problema de saúde (doença mba'eaxy), ou casos de feitiçaria poderia não prescindir de recorrer aos pajés distantes. Situações como essas frequentemente levavam indivíduos para outras aldeias em busca de um xamã - ou pajé. Não era incomum, por exemplo, acionarem-me para buscar rezadores em locais distantes quando alguém precisava ser atendido com certa urgência. A indicação do rezador, normalmente feita pelo próprio doente ou pela família, mobilizava um circuito grande de pessoas e informações entre 
aldeias para adquirir recursos e fazer o deslocamento do pajé ou do doente para o encontro e a sessão de cura.

Se a mobilidade no território fabrica uma dinâmica própria de conformação de um socius que engendra uma estrutura móvel e multilocal; se ela compreende uma ampla cadeia de reciprocidade positiva que se atualiza pelas andanças entre aldeias; se ela engendra um refazer contínuo de um modo autêntico de viver como um guarani - ela expõe, finalmente, uma inquietude natural da pessoa diante das agruras da vida e os esforços para suplantá-las.

As caminhadas são percebidas como constituintes da história desse povo, "índio não tem parada", ouvi frequentemente. "Se alguma coisa não está boa ele pode buscar outro lugar para morar", explicou-me um velho caçador ñandeva. As andanças expressam um "sistema do índio quando em algum momento chega seu tempo e ele precisa mudar de lugar para ficar mais tranquilo", explicavam-me.

A experiência dos deslocamentos entre as aldeias indica haver o constante desejo de trazer à tona um ethos inquieto, "buscador", como denominou Pissolato (2007). Para Tupã Jeguavy, a oguata (caminhada) tem sempre um sentido de preparação, um sentido que se encerra em si mesmo, uma forma para produzir o aperfeiçoamento na pessoa que deve estar sempre atenta àquilo que esse empreendimento pode trazer de novo.

Sobre suas andanças, Karai Poty certa vez insinuou que a constância da alma guarani e sua derradeira permanência está em sobrepujar a condição corruptível da pessoa. "Como isso é possível?", perguntei. “Hoje está difícil, tá tudo diferente”, respondeu. Mas suas falas cotidianas no teko'a depreendem que o valor central da terra reside na possibilidade de refazer continuamente os modos de vida que consideram adequados. Esse "sistema do guarani" inclui um conjunto de práticas e ideias como viver entre parentes e frequentar a casa de reza para fortalecer a pessoa, plantar seus vegetais, "pegar bichinhos e frutinhas no mato". Disso Karai Poty entendia "ser a vida natural". Mas a "terra é pouca, a mata está fraca e o rio está sujo com o veneno que vem das lavouras", explicava. Pelas transformações no espaço geográfico chegaram muitos brancos, cidades foram edificadas, inúmeros objetos e alimentos foram conhecidos e incorporados ao cotidiano guarani. Em busca de um estado de ânimo favorável, de um bem-estar, aventuram-se os guarani constantemente na busca de dias melhores em um mundo imperfeito. 


\section{Algumas considerações}

As mudanças geopolíticas na região engendraram transformações contundentes nos territórios nativos, no espaço social guarani e implicações imediatas sobre os usos da terra, a organização da vida entre parentes, e realização a contento de um modelo de experiência humana. O movimento em busca de terra e os deslocamentos ao longo dos anos dos grupos guarani na região oeste do estado do Paraná permite examinar com acuidade as modificações reais vivenciadas pelo povo guarani naquilo que institui a base ecológica e material de suas condições de vida, reprodução da cultura, e que fundamentalmente diz respeito às suas noções de território.

Nesse sentido, o caminhar e a mobilidade em uma estrutura multilocal e/ou pela reconquista de seus territórios originários estão submetidos àquilo que o movimento de mudança engendra: a reatualização das formas de vida consideradas autênticas. Entretanto, não estão somente em busca de um lugar perfeito que bem sabem está difícil; têm conhecimento sobre as matas derrubadas e os venenos depositados nos rios pela agricultura convencional praticada na região. Mas a experiência dos deslocamentos dessas famílias acena para a possibilidade de se reapropriar do espaço outrora habitado por ancestrais, segundo a memória reservada aos mais antigos, para ali se instalarem com parentes e refazerem continuamente seu mundo social.

\section{Referências}

ASSIS, V. S. Dádiva, mercadoria e pessoa: as trocas na constituição do mundo social mbyá. Porto Alegre: UFRGS, 2006. Tese (Doutorado em Antropologia Social) - Programa de Pós-Graduação em Antropologia Social, Universidade Federal do Rio Grande do Sul, 2006.

ASSIS, V. S. GARLET, I. J. Análise sobre as populações Guarani contemporâneas: demografia, espacialidade e questões fundiárias. Revista de Índias, v. 64, p. 35-54, 2004. Disponível em: $<$ http://revistadeindias.revistas.csic.es/index.php/revistadeindias/article/view/409/477>.

BROCHADO, Jose Proenza. Alimentação na floresta tropical. Porto Alegre: IFCH/UFRS, 1977.

CADOGAN, L. Ayvurapyta: textos míticos de los Mbya Guaraní del Guairá. Asunción: Fundación Leon Cadogan, 1997.

CICCARONE, C. Drama e sensibilidade. Migração, xamanismo e mulheres mbya guarani. São Paulo: PUC, 2001. Tese (Doutorado em Ciências Sociais)- Programa de Pós-Graduação em Ciências Sociais, Pontifícia Universidade Católica de São Paulo, 2001.

CHAMORRO, G. Terra madura, Yvyaragujye: fundamento da palavra guarani. Dourados: Editora UFGD, 2008. 
CLASTRES, H. A Terra sem Mal, o profetismo tupi-guarani. São Paulo: Brasiliense, 1978.

COLODEL, José Augusto. Obrages \& Companhias colonizadora: Santa Helena na história do Oeste paranaense até 1960. Cascavel: Assoeste, 1988.

COLODEL, J. A. Matelândia: História e contexto. Cascavel: Assoeste, 1993.

DARELLA, M. D. P. Ore ropoita yvy porã: nós queremos terra boa.Territorialização guarani no litoral de Santa Catarina. São Paulo: PUC, 2004. Tese (Doutorado em Ciências Sociais) - Programa de Pós-Graduação em Ciências Sociais, Pontifícia Universidade Católica de São Paulo, 2004.

FILIPIM, A. O sistema agrícola Garani Mbyá e seus cultivares de milho: um estudo de caso na aldeia Guarani da Ilha do Cardoso, município de Cananéia, SP. Piracicaba: USP, 2001. Dissertação (Mestrado em Ciências) - Programa de Pós-Graduação em Ciências, Escola Superior de Agricultura Luiz de Queirós, Universidade de São Paulo, Piracicaba, 2001.

FREITAG, L. C. Fronteiras perigosas: migração e brasilidade no extremo oeste paranaense (19371954). Cascavel: Edunioeste, 2001.

GARLET, I. Mobilidade mbyá: história e significação. Porto Alegre: PUC, 1997. Dissertação (Mestrado em História)- Programa de Pós-Graduação em História, Pontifícia Universidade Católica do Rio Grande do Sul, Porto Alegre, 1997.

GRONDIN, M. O alvorecer de Toledo na colonização do oeste do Paraná, 1946-1949. Marechal Cândido Rondon: Germânica, 2007.

LADEIRA, M. I. O caminhar sob a luz.O território Mbyá Guarani e a beira do oceano. São Paulo: Editora da Unesp, 2007.

. Espaço geográfico Guarani-Mbyá: significado, constituição e uso. São Paulo: Editora da Unesp, 2008.

LA SALVIA, F.; BROCHADO, J. P. Cerâmica Guarani. Porto Alegre: Posenato, Arte \& Cultura, 1989.

LITAIFF, A. As divinas palavras: identidade étnica dos Guarani-Mbya. Florianópolis: Editora da UFSC, 1996.

.Les fils Du soleil: mythes et pratiques des indiens Mbya-Guarani du littoral Du Brésil. Montreal: Université de Montréal, 1999. Thèse (Doctorat em Anthropologie)- Faculté des études supérieures, Université de Montreal, 1999.

MACEDO, V. M. Nexos da diferença. Cultura e Afecção em uma aldeia guarani na Serra do Mar. São Paulo: USP, 2009. Tese (Doutorado em Antropologia) - Programa de Pós-Graduação em Antropologia, Universidade de São Paulo, São Paulo, 2009.

MELIÁ, B. A experiência religiosa Guarani. In: MARZAL, M. M. O rosto índio de Deus. Petrópolis: Vozes, 1989.

33, 1990.

A terra sem mal dos guarani. Economia e profecia. Revista de Antropologia, São Paulo, v. 
.El guarani conquistado y reducido. Ensayos de etnohistoria. 4 ed. Asunción: Centro de Estudios Antropológicos de La Universidad Católica, Ceaduc, 1997. $162,2004$.

El pueblo Guarani: unidad e fragmentos. Revista Tellus, Campo Grande, ano 4, n. 6, p. 151-

MELLO, F. C. Aetchá Nhanderu Kuery Karai Retarã: entre deuses e animais. Xamanismo, parentesco e transformações entre os Chiripá e Mbyá Guarani. Florianópolis: UFSC, 2006. Tese (Doutorado em Antropologia Social)- Programa de Pós-Graduação em Antropologia Social, Universidade Federal de Santa Catarina, 2006.

. Mbyá e Chiripá: identidades étnicas, etnônimos e autodenominações entre os Guarani do Sul do Brasil. Revista Tellus, Campo Grande, ano 7, n. 12, p. 49-65, 2007.

MONTEIRO, J. Os guarani e a História do Brasil meridional séculos XVI - XVII. 2 ed. In:CARNEIRO DA CUNHA, M. História dos índios do Brasil. São Paulo: Cia das Letras, 2006.

MOTA, L. T. As guerras dos índios Kaingang: a história épica dos índios kaingang no Paraná (1769-1924). 2 ed. Maringá: Eduem, 2009.

MOTA, L. T.; NOVAK, E. S. Os Kaingang do Vale do Rio Ivaí/PR: História e relações interculturais. Maringá: Editora da Universidade Estadual de Maringá, 2008.

NOELLI, F. S. La distribución geográfica de las evidencias arqueológicas Guaraní. Revista de

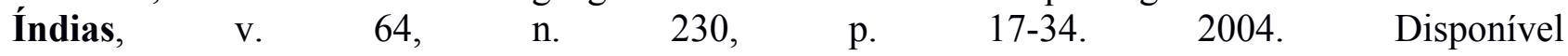
em: $<$ http://revistadeindias.revistas.csic.es/index.php/revistadeindias/article/view/408/476>.

PISSOLATO, E. A duração da pessoa. São Paulo: Unesp, 2007.

QUEZADA, S. E. C. A terra de Nhanderu. Organização sociopolítica e processos de ocupação territorial dos Mbyá Guarani em Santa Catarina, BR. Florianópolis: UFSC, 2007. Dissertação (Mestrado em Antropologia Social) - Programa de Pós-Graduação em Antropologia Social, Universidade Federal de Santa Catarina, Florianópolis,2007.

RIBEIRO, S. I. G. T. Sob o domínio da tradição: um estudo sobre as manifestações do poder nas lideranças políticas guarani (1534-1579). Porto Alegre: UFRGS, 1996. Dissertação (Mestrado em História) - Programa de Pós-Graduação em História, Universidade Federal do Rio Grande do Sul, Porto Alegre, 1996.

O horizonte é a terra. Porto Alegre: UFRGS, 2002. Tese (Doutorado em História) Programa de Pós-Graduação em História, Universidade Federal do Rio Grande do Sul, Porto Alegre, 2002.

SANTOS, C. R. A. Vida material, vida econômica. Curitiba: SEED, 2001. (Coleção História do Paraná)

SCHADEN, E. Aspectos fundamentais da cultura guarani. São Paulo: Edusp, 1974. 
SCHNEIDER, C. I. Contribuição para o estudo de um projeto de colonização no oeste do Paraná: fundamentos socioculturais. In: LOPES, M. A. (Org). Espaços da memória: fronteira. Cascavel: Edinioeste, 2000.

SOARES, A. L. Guarani. Organização social e arqueologia. Porto Alegre: EDIPUCRS, 1997.

SUSNIK, B. Los aborígenes Del Paraguay etnohistoria de los guaranies. Epoca colonial. Asunción: Museo Etnografico Andres Barbero, 1979/80.

TEMPASS, M. Quanto mais doce melhor. Um estudo antropológico das práticas alimentares da doce sociedade Mbyá-Guarani. Porto Alegre: UFRGS, 2010. Tese (Doutorado em Antropologia Social) - Programa de Pós-Graduação em Antropologia Social, Universidade Federal do Rio Grande do Sul, Porto Alegre, 2010.

WACHOWICZ, R. C. Obrageros, Mensus e Colonos. História do Oeste Paranaense. Curitiba: Vicentina, 1982.

Artigo recebido em: 14/08/2015. Artigo aceito para publicação em: 12/09/2015. 